make a diagnosis by the usual evaluation of such properties as density of staining, chromatin dispersion and irregularities in outlines. In this way much of the tedious studying of negative cells is eliminated, freeing the cytologists for more critical evaluation of the suspicious cases.

Field trials are at present under way at the St Helier Hospital, Carshalton, with smears being tested by the VCSA after conventional glass slide evaluation has been made. Dr M. Levene, who is in charge of the tests, thinks that at least another year's trials will be necessary before the reliability of the machine is sufficiently tested. A second machine is on order for the Queen Elizabeth Hospital, Birmingham.

At present the rate of testing is about 1.3 million smears a year. Any woman who has had sexual intercourse is at risk, and there are therefore about 17 million women at risk in Britain. An efficient cytologist can examine about 30 smears a day, while the VCSA can pre-test 200 a day. Final diagnosis of the pre-tested smears by a cytologist is still required, but considerable time can be saved. Vickers estimate that 400 cytologists each with one machine would be enough to screen once a year all the 17 million women at risk in Britain. Each machine costs $£ 6,000$.

If widespread screening is introduced, a considerable amount of treatment will be required, but suggestions that there would be a shortage of bed space were discounted by Professor McLaren of Birmingham, who pointed out that it should prevent the terminal cases which occupy much more space. The lack of enthusiasm of women to be screened is another problem that has vet to be solved.

\section{Hazards of the Pill}

Two reports published in last week's British Medical Journal establish a definite link between the use of oral contraceptives and severe blood clotting in the absence of predisposing conditions. Although the reports do not justify the withdrawal of oral contraceptives from the market, they do at least point out the necessity of avoiding complacency about these preparations, which are, after all, specifically designed to upset the hormonal balance of a woman's body. The authors of the reports are Drs M. P. Vessey and Richard Doll of the Medical Research Council's Statistical Research Unit, and Dr W. H. W. Inman, senior medical officer of the Committee on the Safety of Drugs.

The study by Drs Inman and Vessey was undertaken in direct response to isolated reports submitted to the Committee on the Safety of Drugs concerning the incidence of thromboembolic disease in women using oral contraceptives. Enquiries were therefore made about the use of oral contraceptives by 334 married women aged 20-44 who died during 1966 from thrombosis or embolism of the pulmonary, cerebral or coronary vessels (95, 30 and 209 deaths, respectively). For comparison, information about the use of these preparations was also obtained for a control series of women drawn from the same doctors' practices as those in which the fatalities occurred.

As a result it was estimated that the mortality from pulmonary embolism or cerebral thrombosis attributable to the use of oral contraceptives was $1 \cdot 3$ per annum per 100,000 users aged $20-34$ and $3 \cdot 4$ per annum per 100,000 aged $35-44$. The women who died from coronary thrombosis had been using oral contraceptives more frequently than might have been expected from the experience of the control group, but the difference did not quite attain statistical significance, and no definite link could therefore be established. Inman and Vessey point out, however, that if it is thought justifiable to include deaths from coronary thrombosis, then the mortality attributable to the use of oral contraceptives can be recalculated as 2.2 per 100,000 users in the first age group and 4.5 per 100,000 in the second. There was no evidence to suggest that the risk of thromboembolism is associated with the use of any particular oral contraceptive. Perhaps the most striking feature of the report is that 42 per cent of the women who developed thromboembolic disease had been using oral contraceptives for less than six months.

In the second study, by Vessey and Doll, the medical, obstetric, social, family and contraceptive histories were obtained for a number of women who had been discharged from hospital with a diagnosis of deep vein thrombosis or pulmonary embolism. One hundred and twenty-two patients were selected as controls. The contraceptive preparations used by 23 of the affected patients and eight of the controls were known. It was found that of 58 affected patients, 45 per cent had been using oral contraceptives during the month preceding the onset of their illness while only nine per cent of controls had been doing so. Vessey and Doll concluded that the risk of hospital admission for venous thromboembolism is about nine times greater in women who use oral contraceptives than in those who do not. On the basis of data for the number of women in Great Britain using oral contraceptives, it was estimated that about 1 in every 2,000 women using oral contraceptives is admitted to hospital each year with venous thromboembolism of an obscurc nature as compared with about 1 in every 20,000 women not using them. The existence of a risk of coronary thrombosis was not proved.

Although in these two reports no marked differences can be found bctween various contraceptives, in a leading article in the same issue the British Medical Journal itself suggests that oestrogens may have an effect on blood clotting. Continuous-low-dose-progesterone techniques which do not require oestrogen may therefore afford a means of avoiding thromboembolic effects. Future studies would no doubt be more convincing if samples were larger.

Vascular obstructions accompanying the use of oral contraceptives have also been reported by Drs Celia Oakley and Jane Somerville of the Royal Postgraduate Medical School, Hammersmith Hospital, London, but under different conditions. Writing in last week's Lancet they describe the rapid deterioration in the condition of three patients with congenital septal defects of the heart while taking oral contraceptives. As a result, one of the patients died, and corrective operations for the other two who had previously been suitable for surgery became inadvisable. The two doctors therefore conclude that the contraceptive pill may not be safe in patients with this type of heart disease, particularly when it is associated with raised pulmonary artery pressure.

Other harmful actions of oral contraceptives which have been examined are liver damage and carcinogenesis. So far there is no evidence of a carcinogenic 
action, but changes in liver function and occasional hepatic damage have been noted.

\section{Fertility}

THe birth rate in the United States and the United Kingdom continues to decline. According to figures just released by the National Centre for Health Statistics, the birth rate in the United States in 1967 was 17.9 per thousand compared with 18.4 in 1966 . This is below the 18.4 per thousand level of the depression years 1933 and 1936 , and the absolute number of births in 1967-3.53 million-was also lower than in 1966 - 3.61 million. A much more sensitive indicator of trends in fertility is, of course, the relationship between the annual number of births and the number of women in the child-bearing age group (15 to 44 years old). In 1967, the fertility rate in the United States was 88 per thousand, higher than the 76 per thousand during the depression. Compared with the $1930 \mathrm{~s}$, fewer women are producing more children. The post-war boom in babies in the United States continued unexpectedly for a whole decade and the fertility rate reached a peak of 123 in the late 1950s; since then it has steadily declined to the present level. It remains to be seen whether or not the decline in birth rate reflects only a change in the timing of births or whether there will be a real decline in completed family size. A real decline is expected; with increasing standards parents are choosing to spend more on a few children than take the cheaper by the half dozen outlook. The British population is showing a similar trend. Statistics just released by the Registrar General covering the first quarter of 1968 indicate a continued fall in the birth rate. The rate was $17 \cdot 3$ per thousand compared with 18.1 per thousand and 18.2 per thousand in 1967 and 1966, respectively.

According to the latest United Nations estimates, the world population at the beginning of 1968 was $3.443 \times 10^{9}$; by the end of this year the population is estimated just to exceed $3.5 \times 10^{9}$. The world population will, by then, have increased by $1 \times 10^{9}$ since 1953 and at the present rate the next increase of $1 \times 10^{9}$ is expected within 14 years. In 1967 the population grew most rapidly in Central America and the population of the region may well double in the next twenty years. By contrast at the present rate it will take about 350 years for the population of East Germany to double and about 140 and 63 years to double the populations of Britain and the United States.

\section{Europe's Water}

Soon after May 6, a poster urging water conservation will appear on billboards in the eighteen member countries of the Council of Europe. It will announce the European Clean Water Campaign, which the council is launching at a formal ceremony in Strasbourg on May 6 when the twelve clauses of the European Water Charter will be announced with as much publicity as possible. The Clean Water Campaign is a preliminary part of the European Conservation Year 1970. The precise wording of the Water Charter, which was agreed by the council last May, has not been disclosed, but it stresses the familiar ery that water resources are far from inexhaustible and that water must not be wasted or polluted. Although the whole campaign has been designed to appeal to the general public, it is not aimed at dripping taps or hose pipes but at emphasizing the enhanced amenities that a rational development of water resources would provide for everyone. The council's idea is that, if it can create a climate of public opinion intensely hostile to the squandering of water, national governments, local authorities and industry will all be forced to adopt proper measures to dispose of sewage and industrial wastes and to exploit water supplies.

In Britain, because the campaign is part of the European Conservation Year, the National Parks Commission is to run the national campaign in association with the Ministry of Housing and Local Government and the Water Board. But, relying as it does so heavily on the effect of public opinion, the campaign will certainly need all the support it can muster if it is to be anything other than a damp squib.

\section{Variation on a Theme}

ANother approach to the controversial question of teaching engineering in schools is about to be put into action. Last week it was announced that Shell International Petroleum Company is awarding a grant of $£ 27,000$, spread over three years, to the Institute for Educational Technology at the University of Surrey to support a project designed to further the introduction of engineering and other applications of science into sixth form activities quickly and on a national basis. Mr G. C. Sneed, head of applied science at Ealing Grammar School, has been appointed director of the project.

Mr Sneed points out that able students tend to prefer pure science to more technical subjects, and this may stem from the fact that most of them are given no introduction to technical subjects at school. Several schoolmasters have tried to provide an answer to this problem individually, but recognition of the need for a combined effort led to the setting up in November 1967 of an "action committee" to discuss what could be done. One outcome is the proposed summer school to be held at Imperial College in September of this year, at which teachers will be able to see equipment that has been used successfully by others in introducing technological subjects.

As an important part of the project, Mr Sneed intends to visit different industries and to build models for use in schools of machinery and other equipment, indicating their industrial applications. After about two years, teachers will be able to visit the institute to familiarize themselves with the equipment, and a book containing suggestions for class experiments based on the results of the project will be available. Twelve members of the scientific staff at Surrey University are co-operating with $\mathrm{Mr}$ Sneed, and he will later be joined by another teacher and by technical staff. Mr Sneed's own experience as a teacher is valuable because he has a good idea of what is likely to interest the pupils.

The idea is that engineering and other applied sciences will supplement rather than replace more theoretical subjects such as physics; theory will simply be illustrated and broadened by reference to practical application in industry. Mr Sneed emphasized that the scheme differs from that of the Schools Council's project teams on applied science and tech- 